\title{
An investigation into the variations of moisture content of two buildings constructed with light earth walls. AE/2004/0022091
}

\section{AUTHORS:}

Steven Goodhew*, Richard Griffiths ${ }^{\star *}$ and Chris Morgan ${ }^{\star \star *}$, * Corresponding author, Tel: +44-1752-233664 Fax: +44-1752-233658 e-mail: sgoodhew@plymouth.ac.uk (Steve.Goodhew)

\section{Abstract}

This paper briefly describes the background to light earth buildings and details a series of moisture measurements undertaken upon the clay and straw, (light earth) constructed walls of two UK based buildings. The methodology of measurement that was based upon previous studies undertaken on walls made from straw bales is described. A novel 'in-wall' wet heating system used in one of the two buildings allows the investigation of the effects of direct wall heating upon the distribution of moisture in the walls. The influence of exterior and interior temperature and humidity are described as are the variations in moisture migration introduced by the in-wall heating system. It was concluded that both buildings have exterior wall moisture content readings that indicate little risk of degradation due to interior wall moisture levels (although the Studio walls do exhibit higher and if suffered over long time periods, dangerous moisture readings for part of the measurement period).

CE Database subject headings; Architecture, Buildings, Sustainable development, Construction Materials, Moisture, Environment, Monitoring, Degradation.

\footnotetext{
* Head of Building Programmes, School of Engineering, University of Plymouth, Reynolds Building, Drake Circus, Plymouth, Devon, PL4 8AA. United Kingdom.

**Senior Research Fellow, School of Architecture and Design, University of Plymouth, Hoe Centre, Notte Street, Plymouth, Devon, PL1 2AR, United Kingdom.

***Architect, Locate Architects, 4 Westbank Loan, Portabello Edinburgh, Scotland, EH15 1UB, United Kingdom
} 


\section{Introduction}

Buildings with light earth walls were originally perfected in and around Germany, Europe at the turn of the $19^{\text {th }}$ Century and their walls are constructed from a mixture of clay and straw. Light earth construction was first formally recognised by Willhelm Fauth (Fauth, 1933) but the technique was not widely practised until the 1980's. The seminal work "Leichtlehmbau" (Volhard, 1998) established the term Light Earth Building and was followed by a number of more minor publications describing the technique. Buildings that are built from light earth have walls that have much larger proportions of straw than of clay, by their very nature are organic and are liable to suffer degeneration due to certain combinations of moisture and temperature. This can be exacerbated by the use of inappropriate rendering materials or renders that have poor detailing and/or workmanship which can be the cause of accumulations of moisture within the walls. As Light Earth is used as an infill material, any degeneration of the clay-straw mixture is in itself unlikely to cause any structural problems within any building, but the presence of moisture can lead to reduced thermal performance, increased risk of infestations and general reduction of the functional performance of the building. It is possible, if the Light Earth in-fill became saturated and remained in that condition over long periods of time, any structural members that were constructed from timber or another organic material might also become saturated. This scenario could reduce the bearing capacity of the framing material.

Very little information is available concerning the moisture behaviour of Light Earth infill. However, straw bale buildings have been monitored for moisture changes within walls, as like Light Earth, straw bales are susceptible to changes in moisture content (Goodhew et al, 2004). The monitoring technique chosen replicated the use of sensors located within the walls of the chosen buildings, placed at strategically 
important positions. For further details of the chosen methodology, the reader can view the section concerning the wood disc probe.

The most common method used to measure the moisture content of straw bale wall is the wood disc sensor (Fugler, 2000). The sensors are cheap, straightforward in use and are viewed as being able to accurately match and therefore measure the moisture variations of the surrounding wall material. Fugler's paper compares several series of laboratory-based moisture readings to attempt to calibrate the most commonly utilised design of moisture probe used to monitor strawbale buildings. The paper's analysis of field studies carried out upon three Quebec straw bale houses in 1997 concluded that most straw bales were usually dry enough to avoid rot, but also stated that there '.......are not enough monitored houses to make conclusions'.

\section{The wood disc moisture probe}

The wood disc moisture probe chosen is based upon a design advocated within the work carried out by Canada Mortgage and Housing Corporation and is discussed by Habib Gonzalez, a straw bale builder (Gonzalez, 1998) and Professor Tom Woolly of Queens University Belfast, (Woolly \& Kimmins, 2000).

Figure 1 illustrates a typical wood disc moisture probe.

The wood disc moisture probes were constructed of a $25 \mathrm{~mm}^{2}$ disc of white pine, (as advocated by Gonzalez), 5-mm thick. The disc is drilled in 2 places to make holes 5 $\mathrm{mm}$ apart, although the exact distance is unimportant (Lakinski et al, 2000). Two stainless steel screws are then inserted with a stripped end of a piece of wire wrapped around the head of each screw. The wood disc is then placed at the end of a PVC tube with ventilation holes made around it. The tube can vary in length 
depending upon how deep into the wall it is being placed. In this case the probes were approximately $300 \mathrm{~mm}$ long. The two wires are then run the length of the tube and are joined to two screw terminals, ready for the prongs of a moisture meter. Readings are taken using an electrical resistance timber moisture meter. The moisture content of the wood disc within the probe is influenced by the relative humidity of the bale via the vent holes in the PVC tube, (the accuracy of the probes is discussed in a previous paper (Goodhew et al, 2004)). In this way the moisture content of the light earth wall may be assessed.

Figure $2 \mathrm{~A}$ moisture probe, showing it's relative position relative to the thickness of the walls, 'Littlecroft'.

Each of the probes used in the walls of within the Studio, one of the case study buildings had been modified to take a needle thermometer, which was inserted each time a moisture reading was taken. In this way a broad picture of not only the moisture content of the disc inside the probe could be gained, but also the temperature of the air inside the wall could also be found. Internal humidity and temperature reading were also taken in both case study buildings.

\section{The case study buildings}

The in situ moisture measurements were taken from two buildings, a case study building 'Littlecroft', Borders, Scotland, UK and 'The Studio' situated near Swindon, Wiltshire, UK. Construction of 'The Studio' was finished in November 2000, and a series of moisture probes, were placed at different heights in that walls in all elevations. The walls of 'Littlecroft' were retrofitted in various elevations with moisture probes in December 2002.

\section{Littlecroft Extension}




\section{Construction Details}

The building at Littlecroft is single storey, approximately $5 \mathrm{~m}$ wide externally by $12 \mathrm{~m}$ long, aligned almost exactly North-South and effectively forms one wing of an "L" with the existing cottage for which it acts as a remote (unconnected) extension.

The building has two main rooms and a small store. The northernmost room is a study, the other, larger room acts as a day room and guest bedroom.

The load bearing construction is timber framed with a suspended timber floor structure. The floor and roof are highly insulated with $250 \mathrm{~mm}$ of sheep's wool insulation and the walls are infilled with two types of light earth. The study area, to the north of the building, is completely infilled with woodchip-clay blocks, with a woodchip-clay and sawdust mortar, while the main living room to the south has straw-clay infilled walls.

The walls are rendered with $20 \mathrm{~mm}$ of straw-reinforced clay externally, with a $5 \mathrm{~mm}$ lime harl finish, while a similar clay plaster sub-base internally is finished with a proprietary clay finishing plaster.

\section{Heating}

Heating pipes are installed within the floor depth and the face of the walls, as shown in the images below. The pipes were $10 \mathrm{~mm}$ outer diameter and so were wholly buried within the $25 \mathrm{~mm}$ depth of plaster applied

Figure 4; Two images showing the installation of heating pipes to floor and wall, with subsequent covering by clay plaster and drying patterns showing as the heating is switched on. 
The in-wall/floor heating system was installed by the architects to ensure surface temperatures were higher than the ambient air temperature thus reducing occupant radiant heat loss. By keeping heating emitter surface temperatures low it was hoped to avoid excessive air circulation / convection. The low temperature of the circulating water will also avoid excessive temperature gradients, where the one part of the room is too hot, while another is too cold.

Care was needed in the placing of the moisture probes in the vicinity of the wall heating system for several reasons:

- The heating pipes were vulnerable to puncture or damage from the probes that would penetrate past the interior surface render and deep into the wall itself.

- It was felt to be important to be able to measure the effects of the wall heating system upon the moisture content of the light clay walling material.

- It was also seen as a priority to be able to contrast the 'heated' wall's moisture characteristics with a comparable unheated section of wall.

As can be seen in Figure 5 the heating pipes show-up quite clearly when using a thermographic camera, viewing the internal face of the heated wall. The insulating qualities of the light clay walls prevent enough heat transfer to allow the same identification of the heating pipe work from the exterior. This temperature difference through the cross section of the wall does pose questions concerning the effect of the temperature variation upon the moisture distribution in the area of wall around the heating pipes. 
Figure 5 Thermographic and photographic images showing the wall heating system in the Littlecroft extension.

\section{Rationale for the positioning of the moisture probes at Littlecroft.}

There were a number of reasons for the final location of the probes at Littlecroft, relating to various aspects which could be compared and thus, to a certain extent, gauged independently.

Whilst the building in Swindon, ('the Studio') is completely built with straw-clay, the one in Eildon (Littlecroft) has straw-clay infill to the room to the south (on the right as shown in Figure 6) but with woodchip-clay block infill to the room to the north. These pre-fabricated blocks were introduced for a number of reasons, but one was simply to be able to monitor the relative behaviour of the materials. To this end, probes were inserted in the two east wall sections. Both walls have roughly the same exposure conditions and both have heated and unheated spaces.

Another comparison was related to exposure. Overall, the building at Littlecroft is considerably more sheltered than the Studio in Swindon and so this comparison was felt to be interesting. Between the exposed faces at Littlecroft, the greatest differential of exposure is between the east and west elevations: the west face is generally sheltered, except under unusual north-westerly winds, whilst the east elevation has no immediate shelter. A fairly direct comparison is possible therefore between the 
west, unheated straw-clay wall section and the east, unheated, straw-clay wall section broadly in terms of exposure only.

Another significant difference between the two buildings is the use of heating pipes within the walls at Littlecroft. Given this unusual detail, and the obvious correlation between the temperature in the clay and the probable effect on moisture content, it was felt appropriate to gauge, if possible, the relative behaviour of the two straw-clay panels either side of the door on the west façade.

In common with the building at Swindon, probes were placed at high level, by the ceiling, low level - about 300mm from floor level, and low - about 150mm from floor level, Refer to Figure 6.

Figure 6 showing relative locations of probes at Littlecroft. The two west facing wall sections are both straw-clay filled. Both east facing sections are unheated.

These locations relate to particular concerns about the movement of moisture at the bottom of the wall and the relative moisture levels at the head and foot of the wall generally (Goodhew et al, 2004). Patterns discernible at Littlecroft would be able to be compared to those established over three years at Swindon.

Finally, air temperature and relative humidity sensors were placed in each room of the building and a measurement of these taken at the same time as the probe measurements were taken for reference.

Figure 7; Air temperature and relative humidity sensors 
Figure 8; Drilling a hole for an upper moisture probe.

Figure 9; A lower moisture probe, 'Littlecroft' prior to filling

\section{The Studio}

Each sensor was inserted horizontally into the wall, as shown below.

Figure 10; The position of the moisture sensors in the clay straw wall in the Studio.

The moisture probes were placed in a similar pattern but different spacing to the littlecroft probes. A lower probe, approx. 300mm from floor level, a middle probe 
approx. $600 \mathrm{~mm}$ from floor level and a top probe $300 \mathrm{~mm}$ down from the top of the wall.

Figure 11, Studio building floor plan and wood disc sensor locations.

Results from the moisture probes, exterior and interior sensors for the casestudy buildings.

The results from the moisture probes and the other instrumentation are displayed for each of the case study buildings in turn.

\section{Results of moisture probe readings Littlecroft extension, Eilden, Nr Melrose, Borders, UK.}

As previously described, wood disc moisture probes were placed in a range of wall locations in an attempt to measure moisture, taking into consideration the various combinations of material, height and orientation. To enable the reader to view the different categories of probe location, separate graphs collect together data from related probes and in some instances contrast other pertinent data.

The data is identified using a code system, where, from left to right, the first letter, if W denotes west, $\mathrm{E}$ east etc. The second letter if $\mathrm{H}$ denotes heated, $\mathrm{U}$ unheated, WC woodchip and SC straw clay. The third letter if $U$ refers to the upper probe, (approximately 300mm down from the ceiling), in the medium height probe, (approximately 600mm up from the floor) and $L$ the lower probe (approximately $300 \mathrm{~mm}$ up from the floor). The codes are shown to the legend to the left of each 
chart. Any other readings taken from interior or exterior sensors are labelled in full, such as humidity outside.

Figure 12: Moisture readings - Upper probes - Littlecroft.

The moisture content of the upper probes range from 5.5\%, measured on the heated, west wall, to just over $8 \%$, reached on the east wall. It is interesting to note the average disparity of approximately $2 \%$ between the upper readings of the main two orientations of the building. The average reading over all upper probes was approximately $6.8 \%$.

Figure 13: Moisture readings - Lower probes - Littlecroft.

The average reading from the lower moisture probes is approximately $10.3 \%, 3.5 \%$ higher than the upper probes. The lowest reading, from the unheated, west, wall probe, only drops to the highest recorded readings of the upper probes.

The unheated, west section of the clay straw wall mimics the trends portrayed by the results from the east-facing wall.

Figure 14: Moisture Readings - Probes placed in unheated, west-facing wall Littlecroft 
The middle and lower probes each show similar wall moisture content, both at least $2 \%$ above that recorded by the upper probe.

Figure 15: Moisture readings - Probes placed in west-facing wall with internal heating pipework - Littlecroft.

The results from the west-facing wall panel, with heating pipes placed on the internal face of the clay straw, are similar to the results for the unheated panel. However, the lower probe records moisture data consistently over $11 \%$. As both panels share orientation, are constructed of the same materials, share the same detailing. Thus, any recorded differences can be attributed to the wall heating system.

Figure 16: Moisture content of the east-facing, wood chip clay wall against interior

$$
\text { humidity - Littlecroft }
$$

The wood chip wall sections of the Littlecroft extension were also monitored and had an average moisture reading of approximately $8 \%$. As graph 5 shows, early in the monitoring programme, it can be seen that variation of the moisture of this lower section of the east-facing, wood chip, clay wall follows the variation of internal, relative humidity with time. This relationship appears to be less close, the longer the monitoring has proceeded.

Figure 17: The Moisture content of a range of wall materials and orientations, measured against the variance of outside temperature - Littlecroft.

\section{Results of moisture probe readings the Studio, Wotton Bassett, nr Swindon,} UK. 
Figure 18: Moisture readings - upper probes - The Studio.

From the initial readings taken in late 2000 the moisture levels measured by the bottom probes reached a peak of $27 \%$ in the summer of 2001. A similar winter/summer cycle, but with a lower maximum moisture value.

Figure 19: Moisture readings - middle probes - The Studio.

A similar pattern can be seen in graph 8, however the summer 2001 readings are higher for the middle probes than the lower probes and the second summer moisture readings are marginally lower than the lower probes.

Figure 20: Moisture readings - upper probes - The Studio.

The pattern of the moisture measurements of the upper probes shown in graph 9 does differ from graph 8 . The peak of the summer readings of 2001 is not so pronounced from the west wall, which faces the prevailing wind. The readings for the summer of 2002 are constant compared to the lower sets of wall probes.

Figure 21: Moisture readings - east wall probes - The Studio.

The results from the probes placed in the east facing wall show that the moisture levels for the upper and lower probes do at times vary, but tend to reach the same level eventually.

Figure 22: Moisture readings - west wall probes - The Studio. 
As the west facing wall would suffer the effects of prevailing wind and driven rain, it was felt that this wall would benefit most from a larger number of possible measurements. To this end the greatest numbers of probes were placed in this wall. The results from the probes placed in the top of the west facing wall tend to be drier than the top probes in the east facing wall. This difference is made more apparent as the readings taken from lower down the wall have not reduced as quickly as the east wall lower probes.

Figure 23: Moisture readings - south wall probes - The Studio.

The results from the probes placed in the south facing wall show, much as for the east facing wall, that the moisture levels for the upper and lower probes do at times vary, but tend to reach the same level eventually. 
Figure 24: All moisture readings - compared with the interior relative humidity - The Studio.

The variance in the moisture results from the probes placed in all the walls of the Studio do appear, as a general trend, to follow the interior relative humidity, although there are many other factors may effect the $\% \mathrm{RH}$. The lower probes follow this pattern more closely than the upper probes but the straw clay walls at all heights rose in May 2001 when the interior relative humidity rose from approximately $55 \%$ to $60 \%$.

\section{Conclusions.}

By the end of the measurement period the majority of the walls of both case study buildings have moisture contents in all faces of their outer walls that are below the generally accepted $20-22 \%$ region associated with possible internal material degradation.

The moisture content of the two case study buildings do share some similar patterns in the moisture content distribution within their walls.

Both buildings exhibit lower moisture readings from the moisture probes higher in the walls. The upper probes in the Littlecroft extension varied between $5.5 \%$ and $9 \%$, figure 12, depending upon the orientation and time of year. The upper probes in the Studio varied between $12 \%$ and $28 \%$, graph 9 depending upon the orientation and time of year. 
(it must be stated at this stage in the conclusions that the reader should bear in mind that the Studio was initially built during the wettest November in the UK for ten years and the results from the probes in the Studio started very soon after completion. The Littlecroft extension's monitoring started some months after completion and this may account for the much higher moisture contents generally measured in the time just after the completion of the Studio).

Equally both buildings exhibit higher moisture readings from the moisture probes lower in the walls, although this difference is more marked for the Littlecroft extension. The lower probes in the Littlecroft extension varied between $8 \%$ and $14 \%$, figure 13 , depending upon the orientation and time of year. The upper probes in the Studio varied mostly between $15 \%$ and $29 \%$, Figure 18 depending upon the orientation and time of year.

Orientation also has affected the moisture content of the light earth walls in the Studio but not for the Littlecroft extension when viewing unheated walls. The prevailing wind direction and therefore the most exposed façade is different for both buildings. The west facing side for the Studio whilst the Littlecroft Extension is generally sheltered from most directions. The Studio's east facing probes reached a peak moisture content of approximately $30 \%$ in June 2001 and gradually dried out to below $25 \%$ over the next year, graph 10 . The west facing probes in the Studio did dry to measurements below $20 \%$, the normal 'danger zone' for the anticipation of degradation of organic material, graph 11, but this took considerably longer than drop for the eastern façade.

The interior relative humidity for both buildings was measured and can be seen plotted against the moisture readings in figures 16 and 24. The Littlecroft moisture content readings of the lower part of the eastern wall (wood chip material), do show a 
possible relationship with the variation of interior humidity. As the internal relative humidity readings rise from $60 \%$ to $75 \% \mathrm{RH}$ in the summer of 2003 , the wall moisture readings correspondingly rise from $7 \%$ to $9 \%$. This does beg the question, is the wall, even $100-200 \mathrm{~mm}$ into its thickness, showing the sign of absorbing moisture from the interior of the building?

Figure 17 shows the moisture content of a range of wall materials and orientations, measured against the variance of outside temperature for the Littlecroft extension. The west wall heated probe appears to show no correlation between moisture content of that wall and the exterior temperature. However, the general rise in temperature over 2003 is matched by an increase in moisture content of the woodchip eastern wall as measured by the lower and middle probes. This could be due to the normal increase in ambient exterior moisture content when the exterior temperature increases, and in some way be mimicking the influence of the interior relative humidity shown in figure 16.

As stated in the results section, the moisture readings in the walls of the Studio shown in graph 13 , do as a general trend, follow the interior relative humidity. The lower probes follow this pattern more closely than the upper probes but the moisture content within the straw clay walls at all heights rose in May 2001 when the interior relative humidity rose slightly from $55 \%$ to $60 \%$. This could be an aberration but it is interesting that all the probes in all the walls at all levels, to a greater and lesser extent, respond to the interior relative humidity change.

Figures 14 and 15 show the results from the west-facing wall panel, with and without heating pipes placed on the internal face of the clay straw. Both sets of data are similar however, the lower probe placed in the heated wall panel records moisture 
data consistently over $11 \%$ as compared to around $9 \%$ for the unheated panel. As both panels share orientation, are constructed of the same materials, share the same detailing, any recorded differences can be attributed to the wall heating system. It can be concluded that the wall heating system is 'driving' the moisture away from the warmed parts of the wall panel and 'trapping' the lower moisture close to the lower moisture probe. As the overall moisture content of the lower part of the heated wall panel is still considerably below $20 \%$ there is little cause for concern, but the detailing and general construction of a light- clay property that has wall heating fitted should be appropriate to reduce any risk of moisture ingress, especially at lower walls heights.

It can be generally concluded that both buildings have, over time, exterior wall moisture content readings that indicate that, unless some major degradation of the external façade takes place, have little risk of degradation due to interior wall moisture levels.

\section{Future Work}

Although this study has confirmed that the walls of both buildings have very little danger of degradation due to excessive interstitial moisture there are a few questions still remain.

The moisture performance of light earth buildings that include a heavily used bathroom and kitchen, such as those that might be envisaged in a family home, need to be assessed. As the number of light earth buildings in the UK increase, the opportunities for monitoring will increase and it is hoped that a building of this type could be investigated. 
The use of hybrid designs of walling, such as the use of straw bale, light clay, hemp, cob and other earthen materials could be investigated. It can be seen from the results of this study that earth wood chip walling appears to have the ability to absorb moisture from its surroundings. This property could be used in a number of different situations. This use of different walling systems could be tailored to the areas of occupation that most need the properties exhibited by that walling system.

\section{Acknowledgements}

The authors acknowledge the financial assistance of the DTI UK through the Partners in Industry Programmes which allowed much of this work possible. The Authors also wish to thank Gaia and Locate Architects for their support and the kind help and assistance of Anne Morgan, Neil Cockett and Lysanna Robinson the owners of the two case study buildings.

\section{References}

Anon, (2002) "Goldboard Development Corporation" , Straw’s Botany URL:http://www.goldboard.com/straw/botany/htm 1 March 2002.

Christian, J. E. et al, (1998) "Straw Bale Wall Hot Box Test Results and Analysis", ASRAE Conf, The Thermal Performance of the Exterior Envelopes of Buildings VII -4b103. Florida, December, 1998.

Dill, M.J. (2000) "A Review of Testing for Moisture in Building Elements", Construction Industry Research and Information Association. C538.. 
Fauth, Wilhelm. (1933). Leichtlehmbau, Der Strohlehmstanderbau,

Bauwertschftlicher Siedierlehrdienst H. 3, Eberswalde, Berlin.

Fugler, D., (2000). "Straw Bale Moisture Research", Canada Mortgage and Housing Corporation.

Gonzalez, H. J. (1998) "Home Made Straw Bale Moisture Meters."The Last Straw, Network productions Inc,Spring,1998, Issue No: 22, Page No: 31.

Goodhew, S. M. R., Griffiths ,R. and Woolley, T. (2004). "An investigation of the moisture content in the walls of a straw-bale building". Building and Environment, Elsevier, Accepted Feb 2004, due for publication Autumn 2004.

Lacinski, P. and Bergeron, M. (2000), "Serious Straw Bale." Chelsea Green Publishing Company, 2000.

Steen, A., Steen, B.and Bainbridge, D. (1994). "The Straw Bale House." Chelsea Green Publishing Company,1994.

Swearingen, J. (1998). "Moisture Barriers in Straw Bale Construction." The Last Straw Spring 1998, Issue No: 22, Page No: 8 \& 9.

Volhard, F., (1998). Leichtlehmbau, alter baustoff - neue technik, C.F.Mueller, Heidelberg, 1995, (5 $5^{\text {th }}$ Edition).

Woolley, T. and Kimmins, S. (2000), "Green Building Handbook." Volume 2. London: E \& FN Spon, 2000. 


\section{Bibliography}

Fugler, D. (1998). "Straw Bale Moisture Monitoring." The Last Straw Spring 1998, Issue No: 22, Page No: 30

Fugler,D. (2001). "Straw Bale Moisture Sensor Study." URL:http://mhanet.org/msb/html/papers-n/strwmoist/strwmoist.htm,18 December 2001. 